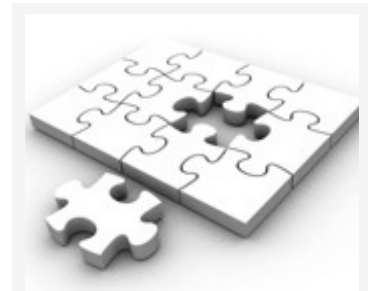

In an effort to facilitate the selection of appropriate peer reviewers for $S A$ Journal of Radiology, we ask that you take a moment to update your electronic portfolio on http:/ / www. sajr.org.za for our files, allowing us better access to your areas of interest and expertise, in order to match reviewers with submitted manuscripts.

If you would like to become a reviewer, please visit the journal website and register as a reviewer.

To access your details on the website, you will need to follow these steps:

1. Log into the online journal at http://www. sajr.org.za

2. In your 'user home' [http://www.sajr.org. za/index.php/sajr/user] select 'edit my profile' under the heading 'my account' and insert all relevant details, bio statement and reviewing interest.

3. It is good practice as a reviewer to update your personal details regularly to ensure contact with you throughout your professional term as reviewer to SA Journal of Radiology.

Please do not hesitate to contact us if you require assistance in performing this task.

Publisher: publishing@aosis.co.za

Tel: +27 219752602

Fax: +27 219754635

\section{SA JOURNAL OF}

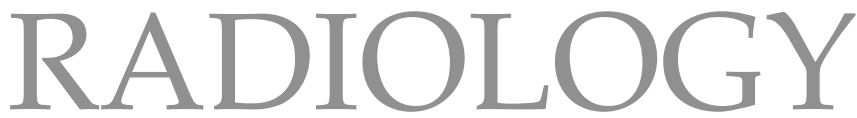

The editorial team of SA Journal of Radiology recognises the value and importance of peer reviewers in the overall publication process - not only in shaping individual manuscripts, but also in shaping the credibility and reputation of our journal.

We are committed to the timely publication of all original, innovative contributions submitted for publication. As such, the identification and selection of reviewers who have expertise and interest in the topics appropriate to each manuscript are essential elements in ensuring a timely, productive peer review process.

We would like to take this opportunity to thank the following reviewers who participated in shaping this issue of SA Journal of Radiology:

\author{
Aadil Ahmed \\ Ahmed Ahidjo \\ Ajmal Ikram \\ Anne-Marie du Plessis \\ Aruna Patil \\ Benjamin Taragin \\ Bev Newman \\ Christelle Ackermann \\ Clive Daniell \\ Darshan Reddy \\ Dilesh Chhiba \\ Dirk van der Merwe \\ Dorothy Bulas \\ Frank A. Imarhiagbe \\ Gloria Soto \\ Hansraj Mangray \\ Hein Els \\ Himal Gajjar \\ Jacqueline du Toit \\ Jaishree Naidoo \\ Jan Lotz \\ Jeanne Lubbe \\ Johan G. Blickman \\ Kassa Darge \\ Kieran McHugh \\ Kimberly Applegate \\ Liesel Davel \\ Mala Modi \\ Maria I. Boechat
}

Marilyn J. Goske

Matthew Goodier

Miranda Durand

Nausheen Khan

Nicky Wieselthaler

Ntobeko A.B. Ntusi

Otto Schulze

Peter Mercouris

R. Minne

R. A.J. Nievelstein

Richard de Villiers

Richard Pitcher

Sally E. Candy

Sam Moore

Sandeep Jakhere

Shalendra K. Misser

Shaun Scheepers

Sherwin Chan

Sinclair Wynchank

Steve J. Beningfield

Suresh K. Chamarthi

Tanyia Pillay

Thomas G. Walker

Tim Cain

Tracy Kilborn

Victor Mngomezulu

Werner Harmse

Zarina Lockhat

We appreciate the time taken to perform your review successfully. 